Christian Irsara, Alexander E. Egger, Wolfgang Prokop, Manfred Nairz, Lorin Loacker, Sabina Sahanic, Alex Pizzini, Thomas Sonnweber, Barbara Holzer, Wolfgang Mayer, Harald Schennach, Judith Loeffler-Ragg, Rosa Bellmann-Weiler, Boris Hartmann, Ivan Tancevski, Günter Weiss, Christoph J. Binder, Markus Anliker, Andrea Griesmacher and Gregor Hoermann*

\title{
Clinical validation of the Siemens quantitative SARS-CoV-2 spike IgG assay (sCOVG) reveals improved sensitivity and a good correlation with virus neutralization titers
}

https://doi.org/10.1515/cclm-2021-0214

Received February 17, 2021; accepted March 24, 2021;

published online April 9, 2021

\section{Abstract}

Objectives: Severe acute respiratory syndrome coronavirus 2 (SARS-CoV-2) infections cause coronavirus disease 2019 (COVID-19) and induce a specific antibody response. Serological assays detecting IgG against the receptor binding domain (RBD) of the spike (S) protein are useful to monitor the immune response after infection or vaccination. The objective of our study was to evaluate the clinical performance of the Siemens SARS-CoV-2 IgG (sCOVG) assay.

*Corresponding author: Gregor Hoermann, MD, PhD, Central Institute of Clinical and Chemical Laboratory Diagnostics, University Hospital of Innsbruck, Anichstrasse 35, 6020 Innsbruck, Austria; and MLL Munich Leukemia Laboratory, Munich, Germany, Phone: +43 50 504-24091, Fax: +43 50 504-24088, E-mail: gregor.hoermann@tirol-kliniken.at Christian Irsara, Alexander E. Egger, Wolfgang Prokop, Lorin Loacker, Markus Anliker and Andrea Griesmacher, Central Institute of Clinical and Chemical Laboratory Diagnostics, University Hospital of Innsbruck, Innsbruck, Austria. https://orcid.org/0000-0003-49018861 (C. Irsara)

Manfred Nairz, Sabina Sahanic, Alex Pizzini, Thomas Sonnweber, Judith Loeffler-Ragg, Rosa Bellmann-Weiler, Ivan Tancevski and Günter Weiss, Department of Internal Medicine II, Infectious Diseases, Pneumology, Rheumatology, Medical University of Innsbruck, Innsbruck, Austria

Barbara Holzer and Boris Hartmann, Department for Animal Health, Austrian Agency for Health and Food Safety (AGES), Moedling, Austria Wolfgang Mayer and Harald Schennach, Central Institute for Blood Transfusion and Immunology (ZIB), University Hospital of Innsbruck, Innsbruck, Austria

Christoph J. Binder, Department of Laboratory Medicine, Medical University of Vienna, Vienna, Austria
Methods: Sensitivity and specificity of the Siemens SCOVG test were evaluated on 178 patients with SARS-CoV2-infection and 160 pre-pandemic samples in comparison with its predecessor test COV2G. Furthermore, correlation with virus neutralization titers was investigated on 134 samples of convalescent COVID-19 patients.

Results: Specificity of the SCOVG test was $99.4 \%$ and sensitivity was $90.5 \%$ (COV2G assay $78.7 \%$; $\mathrm{p}<0.0001$ ). S1-RBD antibody levels showed a good correlation with virus neutralization titers $(r=0.843 ; p<0.0001)$ and an overall qualitative agreement of $98.5 \%$. Finally, median S1-RBD IgG levels increase with age and were significantly higher in hospitalized COVID-19 patients (median levels general ward: $25.7 \mathrm{U} / \mathrm{mL}$; intensive care: $59.5 \mathrm{U} / \mathrm{mL}$ ) than in outpatients $(3.8 \mathrm{U} / \mathrm{mL} ; \mathrm{p}<0.0001)$.

Conclusions: Performance characteristics of the sCOVG assay have been improved compared to the predecessor test COV2G. Quantitative SARS-CoV-2 S1-RBD IgG levels could be used as a surrogate for virus neutralization capacity. Further harmonization of antibody quantification might assist to monitor the humoral immune response after COVID-19 disease or vaccination.

Keywords: COVID-19; neutralization assay; SARS-CoV-2; sensitivity; serology; specificity.

\section{Introduction}

Coronavirus disease 2019 (COVID-19), which is caused by the severe acute respiratory syndrome coronavirus 2 (SARS-CoV-2) [1, 2] was declared pandemic by the WHO on March 11, 2020 [3] and is still challenging the health systems and governments all over the world. As the development of vaccines evolves very rapidly [4] and vaccines are continually approved [5-8] there is a growing need for highly specific and sensitive serologic assays not only for 
supporting COVID-19 diagnosis in the individual patient and for seroprevalence studies but also to estimate the quality and quantity of humoral immune response to vaccination.

Serologic SARS-CoV-2 tests can be categorized by the assay type (neutralization assays [9] vs. immunoassays [10]), the antibody isotype (IgA, IgG, IgM or total antibodies [11]), and type of viral antigen detected (Nucleocapsid [N][12], Spike [S]-protein [13], receptor binding domain [RBD] [14] of the S-protein) and the type of result reporting (qualitative, semi-quantitative, quantitative). The quantification of the humoral immune response to SARS-CoV-2 virus infection or vaccination in large patient cohorts should be performed by an immunoassay, which shows a good correlation to a neutralization assay [15-17]. However, the international harmonization of SARS-CoV-2 serologic assays regarding quantitative values, especially in vaccine recipients, is still pending. The first step toward that goal is the establishment of the first WHO International Standard and Reference Panel for anti-SARS-CoV-2 antibody [18].

Recently, we reported a clinical evaluation of the Siemens SARS-CoV-2 IgG (COV2G) in comparison to three other fully automated SARS-CoV-2 chemiluminescence immunoassays on high throughput random access analyzers (Roche Elecsys Anti-SARS-CoV-2, Abbott SARS-CoV2 IgG, Siemens SARS-CoV-2 total). In that study, the sensitivity of the Siemens COV2G test $(78.8 \%)$ was unexpectedly low and inferior to that of the other assays (range 90.8\%-93\%) [19]. In the meantime, Siemens has launched a new SARS-CoV-2 IgG test (sCOVG) by November 18, 2020. This newly filed assay also detects antibodies against the S1-RBD antigen and is intended to be used for qualitative and quantitative detection of SARS-CoV-2 IgG including neutralizing antibodies [20]. In this study, we aimed to clinically validate this new Siemens SCOVG assay with a particular emphasis on sensitivity using the same samples as in our prior study to ascertain maximal comparability with the previous Siemens COV2G assay. In consideration of the ongoing vaccination programs, we also focussed on validating the potential of the sCOVG assay to quantify IgG antibodies and its correlation with a neutralization assay.

\section{Materials and methods}

\section{Patients and study design}

The present study was performed at the University Hospital of Innsbruck as part of the clinical evaluation of different SARS-CoV-2 serologic assays. All procedures performed in the present study involving human participants were in accordance with the ethical standards of the Institutional and/or National Research Committee and with the 1964 Helsinki declaration and its later amendments and were approved by the Ethics Committee of the Medical University of Innsbruck (Ethics Commission Numbers: 1103/2020, 1167/2020).

A total of 193 patients with reverse transcription polymerase chain reaction (RT-PCR)-confirmed SARS-CoV-2 infection dating between March and August, 2020, were screened for this study. All samples have been previously tested with the Siemens SARS-CoV-2 IgG assay (COV2G) [19]. Fifteen patients (7.8\%) were excluded, as no sample material was available for analysis. The patients' characteristics of the remaining 178 patients are shown in Table 1 . Sensitivity in the investigated cohort was evaluated using one sample per patient dating $\geq 14$ days after disease onset and the sample closest to day 28 after disease onset was chosen. Disease onset was defined as onset of clinical symptoms compatible with COVID-19 infection ( $\mathrm{n}=156,88 \%$ ), or as the first positive SARS-CoV-2 RT-PCR when symptom onset was not available $(\mathrm{n}=22,12 \%)$. Furthermore, 134 samples of RT-PCRconfirmed COVID-19 patients (only one sample per patient) from the CovILD-study cohort [21] were tested in comparison to a SARS-CoV-2 neutralization assay. The patients' characteristics of this cohort are shown in Supplementary Table S1). Of those 134 samples from different patients, 52 (39\%) overlapped with the 178 samples of the sensitivity analysis described above, the remaining $82(61 \%)$ samples were from other patients from the CovILD-study cohort not previously tested in our first assay evaluation study [19]. In addition, 160 prepandemic samples were used to verify specificity. Finally, an intravenous immunoglobulin formulation (Privigen ${ }^{\circledR}, 100 \mathrm{mg} / \mathrm{mL}$, CSL Behring AG, Bern, Switzerland) composed of pre-pandemic pooled immunoglobulins (mainly IgG) of a large number of healthy donors from the US, which should by definition yield negative SARS CoV-2 antibody results, was tested for possible false positive cross reactions.

\section{Siemens SARS-CoV-2 IgG (sCOVG) assay}

The Siemens SARS-CoV-2 IgG (sCOVG) assay was performed in the Central Institute of Clinical and Chemical Laboratory Diagnostics at the University Hospital of Innsbruck. Blood samples were prepared as described previously [19]. We evaluated the Siemens SARS-CoV-2 IgG assay (sCOVG) on the Siemens ADVIA Centaur XP platform (Siemens, Munich, Germany). According to a statement of the manufacturer the former Siemens SARS-CoV-2 IgG assay (COV2G) was modified as follows: The standardization of the SCOVG assay was adjusted as compared to the COV2G assay. The dynamic range for sCOVG was increased to 150 Index compared to 20 for COV2G. Additionally, the standards for the assay were reassigned Index values to effectively make a sample with an Index value of 1 in COV2G would read 2 Index in sCOVG. All samples were processed according to the manufacturer's procedures with the specified controls and calibrators by trained laboratory staff. Results of SARS-CoV-2 IgG are given as U/mL, whereby the cut-off for positivity is defined as $\geq 1.0 \mathrm{U} / \mathrm{mL}$. The manufacturer reports a range of quantification of $0.5-150.0 \mathrm{U} / \mathrm{mL}$, which may be extended to $750.0 \mathrm{U} / \mathrm{mL}$ upon automated 1:5 pre-dilution with the diluent provided by the company. In the sensitivity analysis cohort $(\mathrm{n}=178)$ no pre-dilution was necessary, while in the neutralization assay cohort $(n=134)$ six samples had to be diluted as described. Additional test characteristics given in the manufacturer's product information are summarized in Supplementary Table S2. Precision was evaluated by repeatedly measuring the positive control of the assay. 
Table 1: Characteristics of COVID-19 patients (sensitivity analysis cohort).

\begin{tabular}{|c|c|c|c|c|c|c|c|c|}
\hline & \multicolumn{2}{|c|}{ Total } & \multicolumn{2}{|c|}{ Outpatient } & \multicolumn{2}{|c|}{$\begin{array}{l}\text { Hospitalized } \\
\text { general ward }\end{array}$} & \multicolumn{2}{|c|}{$\begin{array}{l}\text { Hospitalized } \\
\text { intensive care }\end{array}$} \\
\hline & Absolute & $\%$ & Absolute & $\%$ & Absolute & $\%$ & Absolute & $\%$ \\
\hline \multicolumn{9}{|l|}{ Number } \\
\hline $\mathrm{n}$ & 178 & $100 \%$ & 65 & $37 \%$ & 85 & $48 \%$ & 28 & $16 \%$ \\
\hline \multicolumn{9}{|l|}{ Age, years } \\
\hline Min & 20 & & 20 & & 27 & & 44 & \\
\hline Max & 95 & & 83 & & 95 & & 79 & \\
\hline Median (IQR) & $56(43-68)$ & & $39(28-56)$ & & $63(54-76)$ & & $59(54-65)$ & \\
\hline \multicolumn{9}{|l|}{ Sex } \\
\hline Female & 65 & $37 \%$ & 26 & $40 \%$ & 32 & $38 \%$ & 7 & $25 \%$ \\
\hline Male & 113 & $63 \%$ & 39 & $60 \%$ & 53 & $62 \%$ & 21 & $75 \%$ \\
\hline \multicolumn{9}{|c|}{ Symptom onset known } \\
\hline Yes & 156 & $88 \%$ & 47 & $72 \%$ & 82 & $96 \%$ & 27 & $96 \%$ \\
\hline No & 22 & $12 \%$ & 18 & $28 \%$ & 3 & $4 \%$ & 1 & $4 \%$ \\
\hline \multicolumn{9}{|l|}{$\begin{array}{l}\text { Time between } \\
\text { symptom onset } \\
\text { and PCR, days }{ }^{a}\end{array}$} \\
\hline Median (IQR) & $5(2-8)$ & & $2(1-6)$ & & $6(3-8)$ & & $5(2-7)$ & \\
\hline \multicolumn{9}{|c|}{$\begin{array}{l}\text { Time between } \\
\text { disease onset and } \\
\text { blood draw, days }{ }^{b}\end{array}$} \\
\hline Median (IQR) & $47(24-61)$ & & $58(47-68)$ & & $28(19-59)$ & & $28(25-31)$ & \\
\hline
\end{tabular}

IQR, interquartile range; PCR, polymerase chain reaction. ${ }^{a}$ Refers to the first positive SARS-CoV-2 PCR of the patient. ${ }^{b}$ Refers to the representative sample used in the sensitivity analysis.

\section{SARS-CoV-2 neutralization assay}

The SARS-CoV-2 neutralization assay was performed at the Austrian Agency for Health and Food Safety (AGES). Neutralizing antibody titers in human serum and plasma were determined using a tissue culture infectious dose $\left(\mathrm{TCID}_{50}\right.$ ) assay for authentic SARS-CoV-2 virus on Vero 76 clone E6 cells as described [22]. A titer of at least 1:4 defined a positive result in the assay.

\section{Data analysis and statistics}

Statistical analyses were performed using MedCalc, version 19.6.1 (MedCalc Ltd., Ostend, Belgium) and Excel 2016 (Microsoft, Redmont, USA). 95\% confidence intervals (CI) for proportions were calculated according to the Clopper-Pearson exact method. The difference between categorical data was assessed using Chi-square test (McNemar's test for paired data, " $\mathrm{N}$-1" Chi-squared test for unpaired proportions). The difference between quantitative data was assessed using MannWhitney test for two groups and the Kruskal-Wallis test followed by Dunn's post-hoc test for more than two groups. The correlation of quantitative antibody results and the neutralization assay titers was assessed using Spearman's coefficient of rank correlation (rho). Statistical significance was defined at a level of 0.05 .

\section{Results}

\section{Precision}

Intra-assay and inter-run precision for the Siemens SARS-CoV-2 IgG (sCOVG) determined from the assay control (mean antibody level $4.56 \mathrm{U} / \mathrm{mL}$ ) were 3.8\% $(\mathrm{n}=10)$ and $6.1 \%(n=10)$, respectively.

\section{Specificity}

Out of 160 pre-pandemic samples, one tested borderline positive in the Siemens SCOVG assay (Index: 1.24), resulting in a specificity of $99.4 \%$ (95\% CI 96.6-100.0\%, Table 2), which is in line with the manufacturer's claims $(99.90 \%$, 95\% CI 99.64-99.99\%). The measurement of the undiluted pre-pandemic intravenous immunoglobulin formulation Privigen ${ }^{\circledR}$ yielded a borderline positive result $(1.28 \mathrm{U} / \mathrm{mL})$. However, in a more physiologic dilution of 1:50, it yielded a clearly negative result (Supplementary Table S3). 
Table 2: Sensitivity and specificity of the Siemens SCOVG and COV2G assays.

\begin{tabular}{llrr}
\hline & & $\begin{array}{r}\text { Investigated } \\
\text { patient } \\
\text { cohort }\end{array}$ & $\begin{array}{r}\text { Manufacturer's } \\
\text { claims }\end{array}$ \\
\hline Siemens & Sensitivity & $90.5 \%$ & $91.14 \%$ \\
SARS-CoV-2 IgG & (n=178) & $(85.2-94.3)^{\mathrm{a}}$ & $(82.59-96.36)^{\mathrm{b}}$ \\
(sCOVG) & Specificity & $99.4 \%$ & $99.9 \%$ \\
& (n=160) & $(96.6-100.0)$ & $(99.64-99.99)$ \\
Siemens & Sensitivity & $78.7 \%$ & $100.0 \%$ \\
SARS-CoV-2 IgG & (n=178) & $(71.90-84.4)^{\mathrm{a}}$ & $(91.6-100.0)^{\mathrm{b}}$ \\
(COV2G) & Specificity & $100.0 \%$ & $99.9 \%$ \\
& (n=191) & $(98.0-100.00)$ & $(99.6-100.0)$ \\
\hline
\end{tabular}

Sensitivity in the investigated cohort was evaluated using samples of SARS-CoV-2 PCR-confirmed patients dating $\geq 14$ days after disease onset and the sample closest to day 28 after disease onset was chosen (one sample per patient). Only samples in which both, sCOVG and COV2G were tested, were considered. Specificity was determined on pre-pandemic samples. Because of limited sample volume, not all pre-pandemic samples were tested with both assays; all 92 pre-pandemic samples which were tested with both assays resulted negative with both. $95 \%$ confidence intervals are shown in brackets. ${ }^{a} \geq$ Day 14 after disease onset. ${ }^{b} \geq$ Day 14 after first PCR-positivity

\section{Sensitivity}

Out of 178 patients with RT-PCR confirmed SARS-CoV-2 infection, 161 tested positive and 17 negative. Thus the sensitivity was $90.5 \%$ (95\% CI 85.2-94.3\%) for the sCOVG assay (Table 2; Figure 1A). When we compared these results with those of the previous COV2G assay $(78.7 \%, 95 \% \mathrm{CI}$ $71.9-84.4 \%$ ) of the same samples, we found the new sCOVG assay was significantly more sensitive ( $<<0.0001$; Table 2; Figure 1A; Supplementary Figure S1).

When stratifying for gender, age and severity of disease (Figure 1B-D; Supplementary Table S4), the sCOVG assay also had a significantly higher sensitivity than the COV2G assay in male ( $92.9 \%$ vs. $86.7 \%, \mathrm{p}=0.0156$ ), female $(86.2 \%$ vs. $64.6 \%, p=0.0001)$, patients aged $18-49$ years (86.4\% vs. $64.4 \%, \mathrm{p}=0.0002)$, outpatients $(84.6 \%$ vs. $63.1 \%, \mathrm{p}=0.0001)$ and patients at the general ward $(92.9 \%$ vs. $84.7 \%, \mathrm{p}=0.0156)$.

\section{Correlation to the previous Siemens COV2G assay}

When comparing the quantitative index value raw data of the 178 sensitivity samples, the Spearman's coefficient of rank correlation (r) was 0.919 (95\% CI 0.892-0.939, $\mathrm{p}<0.0001$ ) between the sCOVG and the COV2G assay.
However, the scatter diagram (Supplementary Figure S2) shows that in 21/178 (11.8\%) samples, the manufacturer's cut-off index (COI) for positivity was exceeded only in the sCOVG but not the COV2G (lower right quadrant), while vice versa no sample exceeded the COI for positivity in the COV2G but not in the sCOVG assay. 17/178 (9.6\%) samples showed index values below the COI (lower left quadrant) and 140/178 (78.7\%) samples showed an index value above the COI (upper right quadrant) with both assays, respectively. In summary, the raw data index of the formerly COV2G assay correlates with the quantitative results of the new sCOVG test but the new test is better in discriminating values in samples with higher antibody concentrations.

\section{Correlation with SARS-CoV-2 neutralization titers}

Samples of 134 patients of the CovILD-study cohort (Supplementary Table S1) were tested for virus neutralization capacity using a $\mathrm{TCID}_{50}$ assay for authentic SARS-CoV-2 virus. 126 patients (94\%) tested positive for the presence of virus neutralizing antibodies. The sCOVG assay showed an overall qualitative agreement of $98.5 \%$ to the results of the SARS-CoV-2 neutralization test (Supplementary Table S5). Only two samples $(1.5 \%)$ yielded discordant results being positive in the neutralization assay but not in the SCOVG test with 0.3 and $0.6 \mathrm{IU} / \mathrm{mL}$. Importantly, also the quantitative values of antibodies against the RBD of the S-Protein of SARS-CoV-2 showed a good correlation to virus neutralization titers (Spearman's $\mathrm{r}=0.843$, 95\% CI: $0.785-0.885$, $\mathrm{p}<0.0001$; Figure 2).

\section{Patients with severe COVID-19 show higher SARS-CoV-2 S-RBD IgG levels}

Finally, we used the 178 samples of the initial sensitivity cohort in an exploratory analysis to study the impact of patients' and disease characteristics on the quantitative level of IgG antibodies against the S-RBD of SARS-CoV-2 as determined by the Siemens SCOVG assay. Female subjects showed significantly lower quantitative antibody values ( $\mathrm{n}=65$, median $5.59 \mathrm{U} / \mathrm{mL}$, IQR $1.84-29.73 \mathrm{U} / \mathrm{mL}$ ) as compared to males ( $\mathrm{n}=113$, median $23.88 \mathrm{U} / \mathrm{mL}$, IQR 5.6448.79 U/mL; p=0.0003; Figure 3A). Surprisingly, patients aged $18-49$ years also showed markedly lower values $(n=59$, median 4.1 U/mL, IQR 3.2-8.0 U/mL) than patients aged 5069 years $(\mathrm{n}=82$, median $27.2 \mathrm{U} / \mathrm{mL}$, IQR $7.7-53.1 \mathrm{U} / \mathrm{mL}$, $\mathrm{p}<0.0001)$ or patients aged $70-100$ years $(\mathrm{n}=37$, median 25.7 U/mL, IQR 4.5-46.3 U/mL, $\mathrm{p}=0.0032$ ). The difference 
A)

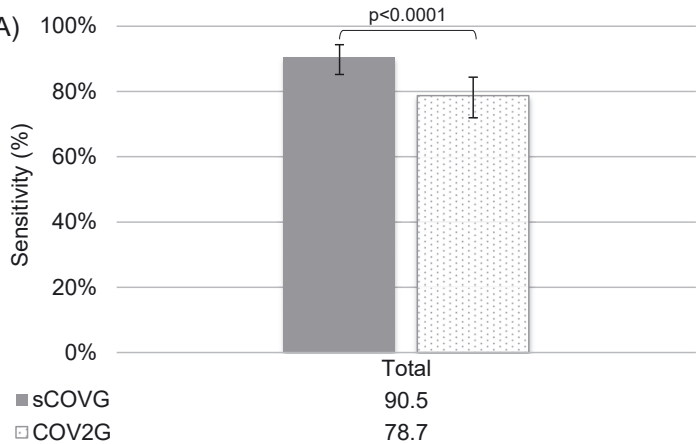

C)
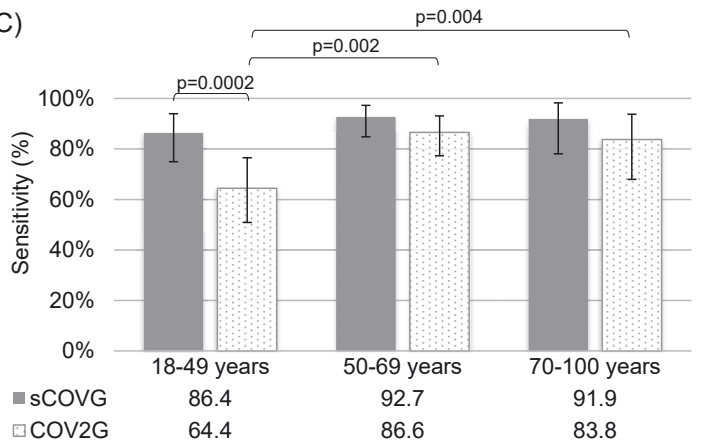

B)
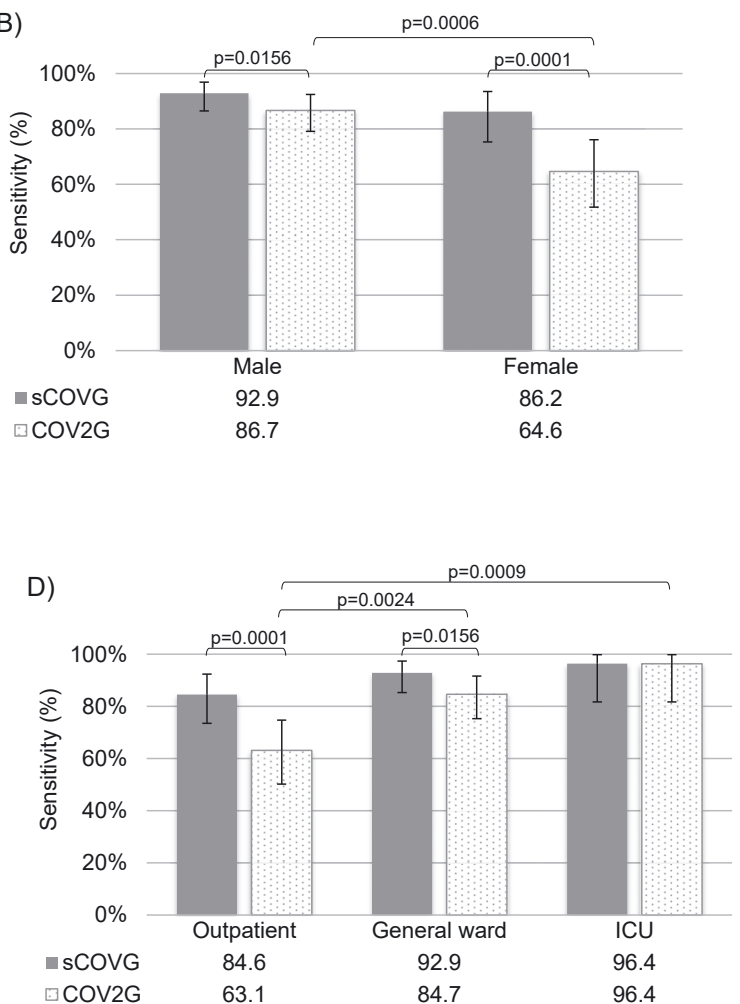

Figure 1: Sensitivity, including subgroup analyses according to gender, age and severity of disease.

Comparison of the sensitivity of the two investigated assays (Siemens SARS-CoV-2 IgG SCOVG in gray, and COV2G dotted) in representative samples of 178 patients with PCR-confirmed COVID-19 (A). Additionally, results were analyzed stratified for gender (B), age (C) and severity of disease (D). The sample numbers for the different cohorts were for female $n=65$, male $n=113$, age $18-49$ years $n=59$, age $50-69$ years $n=82$, age $70-100$ years $n=37$, outpatient $n=65$, patients at the general ward $n=85$ and patients requiring intensive care $n=28$.

between patients aged 50-69 years and patients aged 70100 years was not significant (Figure 3B).

We then asked whether this age dependent increase in serum antibody levels could be linked to disease severity, which is more prevalent in elderly subjects [21, 23]. Outpatients showed clearly and significantly lower antibody values ( $\mathrm{n}=65$, median $3.8 \mathrm{U} / \mathrm{mL}$, IQR $1.4-8.2 \mathrm{U} / \mathrm{mL}$ ) than hospitalized patients either at the general ward $(n=85$, median $25.7 \mathrm{U} / \mathrm{mL}, \mathrm{IQR} 7.5-43.9 \mathrm{U} / \mathrm{mL}, \mathrm{p}<0.0001$ ) or at the ICU ( $\mathrm{n}=28$, median $59.5 \mathrm{U} / \mathrm{mL}$, IQR 36.0-87.8 U/mL, $\mathrm{p}<0.0001$ ). Also, the difference between the patients at the general ward and ICU was statistically significant ( $\mathrm{p}=0.0006$; Figure $3 \mathrm{C}$ ). As the time between the onset of disease and the blood draw for antibody testing was not equal for all cohorts (Supplementary Figure S3) and the kinetics of humoral immune response might influence our results, we restricted the analysis to samples which were drawn at least 30 days after disease onset $(\mathrm{n}=112)$. When considering only those samples, still a similar picture was seen: outpatients $(n=62$, median 3.5 U/mL, IQR 1.3-7.9 U/mL) showed significantly lower antibody values than patients who were previously treated at the general ward $(\mathrm{n}=40$, median $17.6 \mathrm{U} / \mathrm{mL}, \mathrm{IQR}$ 5.8-39.4 U/mL, $\mathrm{p}<0.0001)$ or at the ICU $(\mathrm{n}=10$, median $57.9 \mathrm{U} / \mathrm{mL}, \mathrm{IQR} 23.9-89.6 \mathrm{U} / \mathrm{mL}, \mathrm{p}<0.0001)$. In those samples dated $\geq 30$ days after symptom onset, patients aged 18 49 years $(\mathrm{n}=51$, median $3.6 \mathrm{U} / \mathrm{mL}, \mathrm{IQR} 1.8-8.7 \mathrm{U} / \mathrm{mL}$ ) showed significantly lower antibody values than patients aged 50 69 years $(\mathrm{n}=47$, median $12.6 \mathrm{U} / \mathrm{mL}, \mathrm{IQR} 5.2-34.1 \mathrm{U} / \mathrm{mL}$, $\mathrm{p}=0.0019)$.

\section{Discussion}

Our clinical evaluation of the Siemens SARS-CoV-2 IgG (sCOVG) showed improved sensitivity compared to the previous COV2G test. Quantitative results for S-RBD IgG levels determined with this assay correlated with SARS-CoV-2 neutralization titers and the severity of COVID-19.

In our previous evaluation of the former Siemens COV2G test, we compared the performance characteristics of the Roche Elecsys Anti-SARS-CoV-2, Abbott SARS-CoV-2 


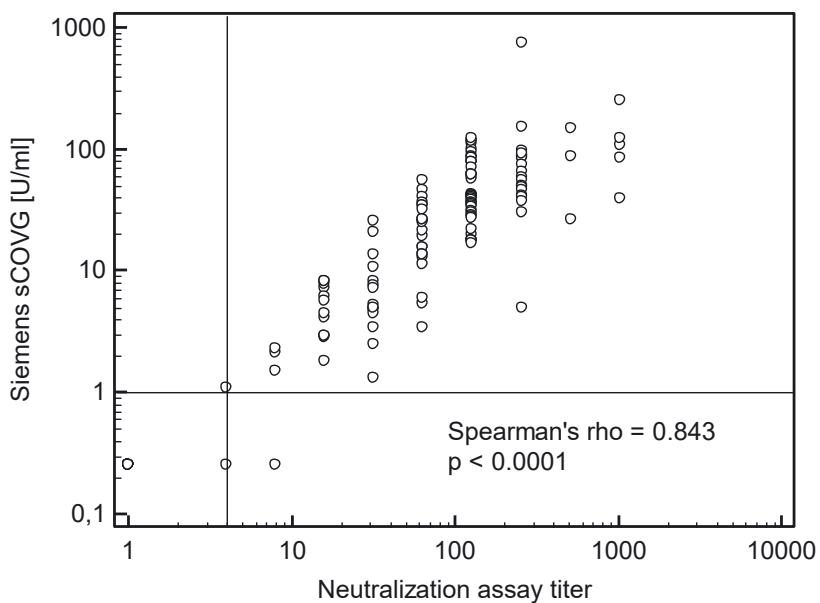

Figure 2: Correlation between the quantitative Siemens SARS-CoV$2 \operatorname{lgG}(\mathrm{sCOVG}, \mathrm{U} / \mathrm{mL}$ ) value and the neutralization assay titer in 134 samples of different SARS-CoV-2 RT-PCR confirmed patients. The horizontal line shows the COI for positivity of the SCOVG assay $(\geq 1.0 \mathrm{U} / \mathrm{mL}$ ), the vertical line shows the cut off for positivity of the neutralization assay (titer level $\geq 4$ ). For this illustration, values below the limit of quantification ( $L o Q, 0.5)$ in the SCOVG test were set as $0.25 \mathrm{U} / \mathrm{mL}$, neutralization assay titers < 4 were set as 1 and titers > 512 as 1,024 .

IgG, Siemens SARS-CoV-2 total (COV2T) and SARS-CoV-2 IgG (COV2G), and found a markedly lower sensitivity of the Siemens COV2G (78.8\%) compared to all other assays. In contrast, the new Siemens sCOVG was significantly more sensitive (90.5\%). This is well in line with the sensitivities observed for all other assays evaluated with our cohort (range 90.4\%-93\%) [19]. Additionally, the sensitivity is essentially in line with the manufacturer's claims, which state a sensitivity of $91.14 \%$ for samples between day 14-20 after PCR-diagnosis and $96.41 \%$ for samples dated $\geq 21$ days after PCR diagnosis (Supplementary Table S1). Still, the rate of COVID-19 patients without detectable antibody response with various assays in our cohort is higher than reported by several manufacturers. On the one hand, this might be partly explained by the inclusion of patients with immunosuppression in our study [19]. In this regard, 9 out of the 13 samples which gave concordantly negative results with four diverse serologic assays in our previous study (mainly due to immunosuppressive therapy of those patients, including chemotherapy, anti-CD20 antibodies and cortisone), were included in this study and all resulted negative with the sCOVG assay too. On the other hand, a number of manufacturer independent studies reported real-life data that are well comparable to our results [24-29]. Specificity was $>99 \%$ and thus within the specifications of the manufacturer. We observed no obvious differences in specificities between the COV2G and the sCOVG test although our study was not powered to detect small differences. Thus, the performance characteristics
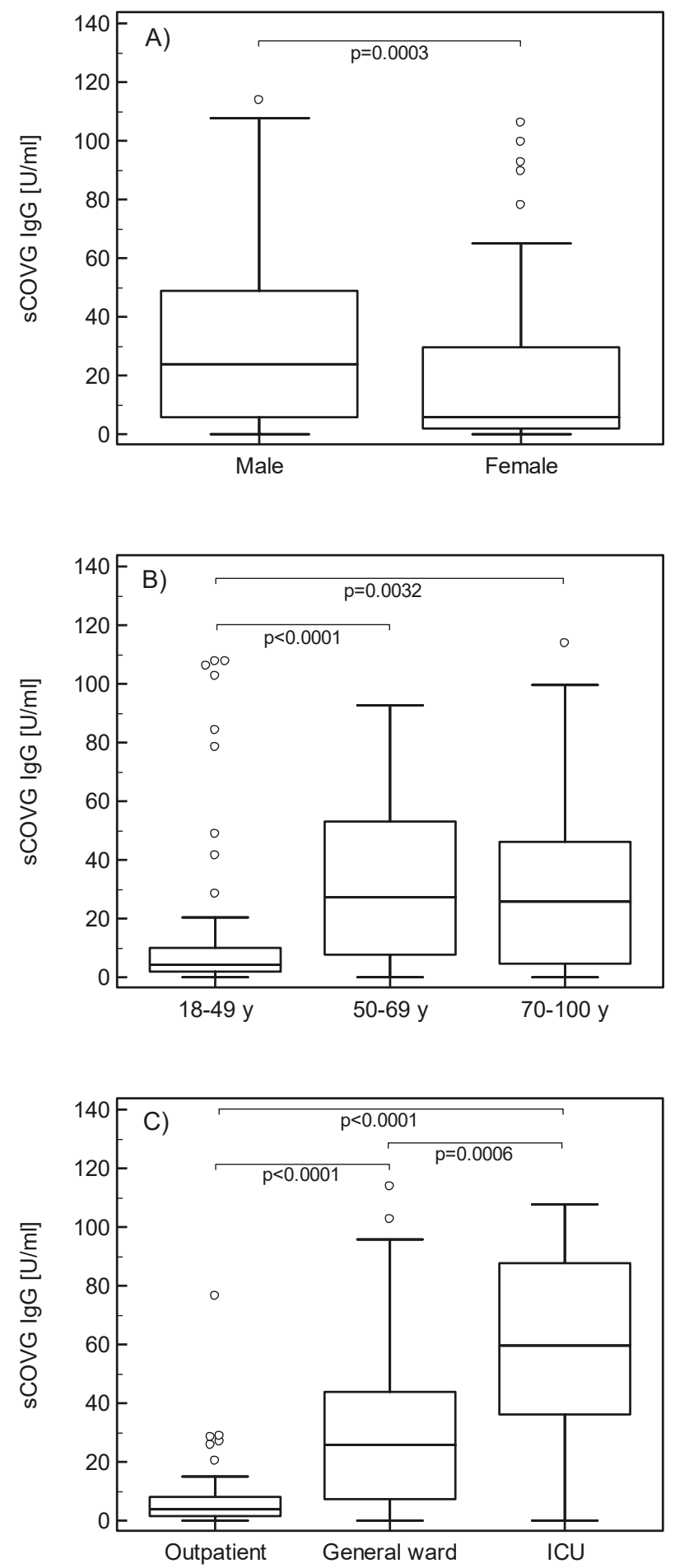

Figure 3: $(A-C)$ Comparison of the quantitative values $(U / m L)$ of the Siemens SARS-CoV-2 IgG (sCOVG) assay depending on gender, age and severity of disease.

The quantitative values of the 178 samples of different SARS-CoV-2 RT-PCR-confirmed patients were analyzed according to gender (A), age (B) and severity of disease (C). The sample numbers for the different cohorts were for female $n=65$, male $n=113$, age $18-49$ years $n=59$, age $50-69$ years $n=82$, age $70-100$ years $n=37$, outpatient $\mathrm{n}=65$, patients at the general ward $\mathrm{n}=85$ and patients requiring intensive care (ICU) $n=28$. 
regarding specificity and sensitivity of the Siemens sCOVG assay are basically in line with those observed for other fully automated chemiluminescence immunoassays run on high throughput random access analyzers [15-20] and with the information given by the manufacturer. Measurement of a pre-pandemic intravenous immunoglobulin formulation (Privigen ${ }^{\circledR}$ ) in a physiologic (1:50) dilution yielded a clearly negative sCOVG result, indicating that pre-pandemic formulations of this intravenous immunoglobulin preparation should not shield false positive results in recipients of this therapy. However, it is expected that in the future COVID-19 convalescent plasma donors will be included in the production process of such preparations and could then potentially lead to false positive serologic results in the recipients.

We previously found a lower rate of antibody positivity in the COV2G in females than in males [19]. This difference was not significant for the new SCOVG assay as the clinical sensitivity was improved for all sub-cohorts. In this regard, the sCOVG seems to detect the previous COVID-19 infection more robustly. However, the quantitative S1-RBD IgG levels were significantly higher in males compared to females in our study, which is in line with higher anti-S- and $\mathrm{N}$-antibodies [30] or higher anti-S-antibodies and neutralizing antibodies in male than in female subjects [31] in other studies, respectively. Similarly, a significantly lower rate of antibody positivity has been observed for outpatients compared to hospitalized patients with the former COV2G assay [19] but not with the new sCOVG assay. Again, the quantitative S-RBD IgG levels correlated with the severity of the disease in our study. Rijkers et al. found higher RBD total antibodies and higher neutralizing antibody titers in severe (hospitalized) vs. mild (non-hospitalized) COVID-19 patients [32]. Also, other authors described that severe COVID-19 patients had a more vigorous Ig [33, 34] and higher neutralizing antibody response [35]. This would be in line with the observation of higher levels of antibodies in elderly patients as they have a higher prevalence of complicated disease [23]. Moreover, complicated disease is associated with more pronounced immune activation and sustained inflammation [36, 37], which may translate into more sustained immune responses and higher antibody titers. However, some authors did not find an association between antibody response [38] or neutralizing antibody response [39] and disease severity. The reasons for the discrepancies between these reports remain unknown but may involve differences in the study design, patient cohorts or types of immunoassays used.

The quantification of SARS-CoV-2 IgG levels is an additional benefit of the SCOVG assay compared to its predecessor COV2G and may aid to monitor the antibody levels after COVID-19 or after vaccination over time [40-43]. In this regard, further harmonization of antibody measurement is ongoing to standardize the monitoring of humoral immune response in the future and to estimate the degree of protection and to predict its likely duration [18]. Assays detecting antibodies against the RBD of the S-Protein of SARS-CoV-2 might be of particular interest as they also detect neutralizing antibodies interfering with the binding of the SARS-CoV-2 to the ACE receptor $[14,15]$. In our study, we found a good qualitative and quantitative correlation of the SCOVG result with a SARS-CoV-2 virus neutralization assay in 134 COVID-19 patients. Only two (1.5\%) out of all 134 samples showed discrepant qualitative results, and in both cases the neutralization assay was positive while the SCOVG remained below the threshold for positivity. Conversely, all sCOVG-positive samples had a positive neutralization assay result. However, the pre-test probability needs to be considered, as this part of our study was limited to patients recovered from COVID-19 and who thus had a high likelihood of having mounted a neutralizing antibody response. In other cohorts including individuals without COVID-19 infection or vaccination, the potential of false positive results needs to be considered for serologic testing. SARS-CoV-2 IgG has been shown to correlate with virus neutralizing titers [44]. Moreover, S-protein based immunoassays correlate better with neutralizing activity than N-protein based assays [15]. For the S1-RBD based Siemens SCOVG, we found a higher correlation with a neutralization assay than other authors for other immunoassays [15-17]. Our study was not designed to measure antibody level kinetics over time ant thus this question remains one major limitation of it and warrants further studies to answer this important aspect.

It is currently unclear if serological testing is of clinically need for individuals after COVID-19 vaccination. IgG against the S-protein of SARS-CoV-2 is typically found after vaccination [45-47]. Prerequisites for assays for estimating the humoral immune response to COVID-19 vaccinations at the individual level include the usage of the correct antigen (e.g. the S-protein for the mRNA-based vaccines BNT162b2 from Biontech/Pfizer and mRNA-1273 from Moderna and for AstraZenecas adenoviral vector-based vaccine ChAdOx1 [41-43]) and the correct antibody isotype (IgG, due to their longevity [48]), the potential to quantify the results and a good correlation of antibody results with the presence of neutralizing antibodies. The sCOVG test potentially fulfills all those criteria. However, further studies with standardized quantification of SARS-CoV-2S(-RBD) IgG are expected to provide a useful surrogate for virus neutralization capacity and to establish the basis for clinically relevant antibody level cut-offs after SARS-CoV-2 infection 
and vaccination. Ideally, the peak levels and dynamics of antibody levels will enable us to predict the extent and the duration of immunity against COVID-19.

In summary, we performed an independent clinical evaluation of the quantitative Siemens SARS-CoV-2 IgG (sCOVG) assay. To the best of our knowledge, this is the first published external validation of this test for IgG antibodies against the S-RBD of SARS-CoV-2. The assay showed improved sensitivity compared to the predecessor test COV2G. Overall, specificity and sensitivity of the sCOVG assay are comparable to those observed for other fully automated chemiluminescence immunoassay tests on high throughput random access analyzers in our cohort. Comparisons with the results from a SARS-CoV-2 neutralization assay indicate a good correlation with the SCOVG S1-RBD IgG levels in convalescent COVID-19 patients. In the future, the quantification of SARS-CoV-2 S-RBD IgG antibody response will be of interest not only to monitor the humoral immune response after COVID-19 disease but also upon vaccination.

Acknowledgments: The authors thank Gernot Osterer (Siemens) for technical support.

Research funding: The study was performed by institutional research funding.

Author contributions: $\mathrm{CI}, \mathrm{AE}$, WP, LL, CJB, MA, AG, and GH performed or analyzed serological tests. BHo and $\mathrm{BHa}$ performed virus neutralization tests. SS, AP, TS, WM, HS, JL-R, RB-W, IT, and GW obtained clinical data. CI and AE performed statistical analysis. $\mathrm{CI}, \mathrm{AE}, \mathrm{AG}$, and GH designed the study and wrote the paper. All authors revised and approved the manuscript.

Competing interests: CJB is board member of Technoclone $\mathrm{GmbH}$. The other authors declare no competing interest.

Informed consent: Patients included in this study gave informed consent.

Ethical approval: All procedures performed in the present study involving human participants were in accordance with the ethical standards of the Institutional and/or National Research Committee and with the 1964 Helsinki declaration and its later amendments and were approved by the ethics committee of the Medical University of Innsbruck (Ethics Commission Numbers: 1103/2020, 1167/2020).

\section{References}

1. Zhu N, Zhang D, Wang W, Li X, Yang B, Song J, et al. A novel Coronavirus from patients with pneumonia in China, 2019. N Engl J Med 2020;382:727-33.
2. Guan WJ, Ni ZY, Hu Y, Liang WH, Ou CQ, He JX, et al. Clinical characteristics of Coronavirus disease 2019 in China. N Engl J Med 2020;382:1708-20.

3. World Health Organization. Virtual press conference on COVID-19-11 March 2020. Available from: https://www.who.int/ docs/default-source/coronaviruse/transcripts/who-audioemergencies-coronavirus-press-conference-full-and-final11mar2020.pdf?sfvrsn=cb432bb3_2 [Accessed 20 Oct 2020].

4. Forni G, Mantovani A. Covid-19 Commission of Accademia Nazionale dei Lincei R. COVID-19 vaccines: where we stand and challenges ahead. Cell Death Differ 2021;28:626-39.

5. European Medicines Agency (EMA). Section COVID-19 treatments and vaccines - authorised medicines. Available from: www.ema.europa.eu [Accessed 28 Jan 2021].

6. U.S. Food and Drug Administration (FDA). Section COVID-19: COVID-19 vaccines. Available from: www.fda.gov [Accessed 28 Jan 2021].

7. Burki TK. The Russian vaccine for COVID-19. Lancet Respir Med 2020;8:e85-6.

8. World Health Organization (WHO). Section COVID-19 vaccines. Available from: https://www.who.int/emergencies/diseases/ novel-coronavirus-2019/covid-19-vaccines [Accessed 28 Jan 2021].

9. Riepler L, Rossler A, Falch A, Volland A, Borena W, von Laer D, et al. Comparison of four SARS-CoV-2 neutralization assays. Vaccines (Basel) 2020;9.

10. Centers for Disease Control and Prevention. Interim guidelines for COVID-19 antibody testing in clinical and public health settings. Available from: https://www.cdc.gov/coronavirus/ 2019-ncov/lab/resources/antibody-tests-guidelines.html [Accessed 18 Dec 2020].

11. Post N, Eddy D, Huntley C, van Schalkwyk MCl, Shrotri M, Leeman D, et al. Antibody response to SARS-CoV-2 infection in humans: a systematic review. PLoS One 2020;15:e0244126.

12. Zeng W, Liu G, Ma H, Zhao D, Yang Y, Liu M, et al. Biochemical characterization of SARS-CoV-2 nucleocapsid protein. Biochem Biophys Res Commun 2020;527:618-23.

13. Herrera NG, Morano NC, Celikgil A, Georgiev GI, Malonis RJ, Lee $\mathrm{JH}$, et al. Characterization of the SARS-CoV-2 S protein: biophysical, biochemical, structural, and antigenic analysis. ACS Omega 2021;6:85-102.

14. Lan J, Ge J, Yu J, Shan S, Zhou H, Fan S, et al. Structure of the SARS-CoV-2 spike receptor-binding domain bound to the ACE2 receptor. Nature 2020;581:215-20.

15. Therrien C, Serhir B, Belanger-Collard M, Skrzypczak J, Shank DK, Renaud C, et al. Multicenter evaluation of the clinical performance and the neutralizing antibody activity prediction properties of ten high throughput serological assays used in clinical laboratories. J Clin Microbiol 2020;59:e02511-20.

16. Padoan A, Bonfante F, Pagliari M, Bortolami A, Negrini D, Zuin S, et al. Analytical and clinical performances of five immunoassays for the detection of SARS-CoV-2 antibodies in comparison with neutralization activity. EBioMedicine 2020;62:103101.

17. Bal A, Pozzetto B, Trabaud MA, Escuret V, Rabilloud M, Langlois-Jacques $C$, et al. Evaluation of high-throughput SARSCoV-2 serological assays in a longitudinal cohort of patients with mild COVID-19: clinical sensitivity, specificity and association with virus neutralization test. Clin Chem 2021. https://doi.org/ 10.1093/clinchem/hvaa336. 
18. Haddad M. World Health Organization (WHO). WHO/ BS.2020.2403 establishment of the WHO International Standard and Reference Panel for anti-SARS-CoV-2 antibody. Available from: www.who.int/publications/m/item/WHO-BS-2020.2403 [Accessed 5 Feb 2021].

19. Irsara C, Egger AE, Prokop W, Nairz M, Loacker L, Sahanic S, et al. Evaluation of four commercial, fully automated SARS-CoV-2 antibody tests suggests a revision of the Siemens SARS-CoV-2 IgG assay. Berlin: Clinical Chemistry and Laboratory Medicine (CCLM); 2021.

20. Siemens Healthineers AG. Available from: https://www.siemenshealthineers.com/press-room/press-releases/covid-19-iggquantitative.html [Accessed 28 Jan 2021].

21. Sonnweber T, Sahanic S, Pizzini A, Luger A, Schwabl C, Sonnweber B, et al. Cardiopulmonary recovery after COVID-19: an observational prospective multi-center trial. Eur Respir J 2020. https://doi.org/10.1183/13993003.03481-2020.

22. Klausberger M, Dürkop M, Haslacher H, Wozniak-Knopp G, Cserjan-Puschmann M, Perkmann T, et al. A comprehensive antigen production and characterization study for easy-toimplement, highly specific and quantitative SARS-CoV- 2 antibody assays. medRxiv 2021:2021.01.19.21249921.

23. Karagiannidis C, Mostert C, Hentschker C, Voshaar T, Malzahn J, Schillinger G, et al. Case characteristics, resource use, and outcomes of 10021 patients with COVID-19 admitted to 920 German hospitals: an observational study. Lancet Respir Med 2020;8:853-62.

24. Schnurra C, Reiners N, Biemann R, Kaiser T, Trawinski H, Jassoy C. Comparison of the diagnostic sensitivity of SARS-CoV-2 nucleoprotein and glycoprotein-based antibody tests. J Clin Virol 2020;129:104544.

25. Manthei DM, Whalen JF, Schroeder LF, Sinay AM, Li SH, Valdez R, et al. Differences in performance characteristics among four highthroughput assays for the detection of antibodies against SARSCoV-2 using a common Set of patient Samples. Am J Clin Pathol 2020;155:267-79.

26. Hörber S, Soldo J, Relker L, Jurgens S, Guther J, Peter S, et al. Evaluation of three fully-automated SARS-CoV-2 antibody assays. Clin Chem Lab Med 2020;58:2113-20.

27. Weidner L, Gansdorfer S, Unterweger S, Weseslindtner L, Drexler C, Farcet M, et al. Quantification of SARS-CoV-2 antibodies with eight commercially available immunoassays. J Clin Virol 2020; 129:104540.

28. Risch M, Weber M, Thiel S, Grossmann K, Wohlwend N, Lung T, et al. Temporal course of SARS-CoV-2 antibody positivity in patients with COVID-19 following the first clinical presentation. BioMed Res Int 2020;2020:9878453.

29. Perkmann T, Perkmann-Nagele N, Breyer MK, Breyer-Kohansal R, Burghuber OC, Hartl S, et al. Side-by-Side comparison of three fully automated SARS-CoV-2 antibody assays with a focus on Specificity. Clin Chem 2020;66:1405-13.

30. Korte W, Buljan M, Rosslein M, Wick P, Golubov V, Jentsch J, et al. SARS-CoV-2 IgG and IgA antibody response is gender dependent; and IgG antibodies rapidly decline early on. J Infect 2020;82 e11-4.

31. Klein SL, Pekosz A, Park HS, Ursin RL, Shapiro JR, Benner SE, et al. Sex, age, and hospitalization drive antibody responses in a
COVID-19 convalescent plasma donor population. J Clin Invest 2020;130:6141-50.

32. Rijkers G, Murk JL, Wintermans B, van Looy B, van den Berge M, Veenemans J, et al. Differences in antibody kinetics and functionality between Severe and mild Severe Acute respiratory Syndrome Coronavirus 2 Infections. J Infect Dis 2020;222: 1265-9.

33. Liu X, Wang J, Xu X, Liao G, Chen Y, Hu CH. Patterns of IgG and IgM antibody response in COVID-19 patients. Emerg Microb Infect 2020;9:1269-74.

34. Schaffner A, Risch L, Aeschbacher S, Risch C, Weber MC, Thiel SL, et al. Characterization of a pan-Immunoglobulin assay quantifying antibodies directed against the Receptor binding domain of the SARS-CoV-2 S1-subunit of the Spike protein: a population-based Study. J Clin Med 2020;9. https://doi.org/10. $3390 / \mathrm{jcm} 9123989$.

35. Chen X, Pan Z, Yue S, Yu F, Zhang J, Yang Y, et al. Disease severity dictates SARS-CoV-2-specific neutralizing antibody responses in COVID-19. Signal Transduct Target Ther 2020;5:180.

36. Bellmann-Weiler R, Lanser L, Barket R, Rangger L, Schapfl A, Schaber $M$, et al. Prevalence and predictive value of anemia and dysregulated iron homeostasis in patients with COVID-19 Infection. J Clin Med 2020;9. https://doi.org/10.3390/ jcm9082429.

37. Manson JJ, Crooks C, Naja M, Ledlie A, Goulden B, Liddle T, et al. COVID-19-associated hyperinflammation and escalation of patient care: a retrospective longitudinal cohort study. Lancet Rheumatol 2020;2:e594-602.

38. Phipps WS, SoRelle JA, Li QZ, Mahimainathan L, Araj E, Markantonis J, et al. SARS-CoV-2 antibody Responses do not predict COVID-19 disease Severity. Am J Clin Pathol 2020;154: 459-65.

39. Koblischke M, Traugott MT, Medits I, Spitzer FS, Zoufaly A, Weseslindtner L, et al. Dynamics of CD4 T cell and antibody Responses in COVID-19 patients with different disease Severity. Front Med (Lausanne) 2020;7:592629.

40. Crawford KHD, Dingens AS, Eguia R, Wolf CR, Wilcox N, Logue JK, et al. Dynamics of neutralizing antibody titers in the months after SARS-CoV-2 infection. J Infect Dis 2020;223:197-205.

41. Voysey M, Clemens SAC, Madhi SA, Weckx LY, Folegatti PM, Aley $\mathrm{PK}$, et al. Safety and efficacy of the ChAdOx1 $\mathrm{nCoV}-19$ vaccine (AZD1222) against SARS-CoV-2: an interim analysis of four randomised controlled trials in Brazil, South Africa, and the UK. Lancet 2021;397:99-111.

42. Baden LR, El Sahly HM, Essink B, Kotloff K, Frey S, Novak R, et al. Efficacy and safety of the mRNA-1273 SARS-CoV-2 vaccine. $N$ Engl J Med 2020;384:403-16.

43. Polack FP, Thomas SJ, Kitchin N, Absalon J, Gurtman A, Lockhart $\mathrm{S}$, et al. Safety and efficacy of the BNT162b2 mRNA covid-19 vaccine. N Engl J Med 2020;383:2603-15.

44. Salazar E, Kuchipudi SV, Christensen PA, Eagar T, Yi X, Zhao P, et al. Convalescent plasma anti-SARS-CoV-2 spike protein ectodomain and receptor-binding domain IgG correlate with virus neutralization. J Clin Invest 2020;130:6728-38.

45. Walsh EE, Frenck RW, Jr., Falsey AR, Kitchin N, Absalon J, Gurtman A, et al. Safety and Immunogenicity of two RNA-based covid-19 vaccine candidates. N Engl J Med 2020;383:2439-50. 
46. Jackson LA, Anderson EJ, Rouphael NG, Roberts PC, Makhene M, Coler RN, et al. An mRNA vaccine against SARS-CoV-2: preliminary Report. N Engl J Med 2020;383:1920-31.

47. Folegatti PM, Ewer KJ, Aley PK, Angus B, Becker S, BelijRammerstorfer $S$, et al. Safety and immunogenicity of the ChAd0x1 $\mathrm{nCoV}-19$ vaccine against SARS-CoV-2: a preliminary report of a phase $1 / 2$, single-blind, randomised controlled trial. Lancet 2020;396:467-78.
48. Zhang X, Lu S, Li H, Wang Y, Lu Z, Liu Z, et al. Viral and antibody kinetics of COVID-19 patients with different disease severities in Acute and convalescent phases: a 6-month follow-up Study. Virol Sin 2020;35:820-9.

Supplementary Material: The online version of this article offers supplementary material (https://doi.org/10.1515/cclm-2021-0214). 